\title{
Integrating regional climate change into allometric equations for estimating tree aboveground biomass of Masson pine in China
}

\author{
Liyong $\mathrm{Fu}^{1} \cdot$ Xiangdong $\mathrm{Lei}^{1} \cdot{\mathrm{Znongda} \mathrm{Hu}^{2} \text { - Weisheng Zeng }}^{3} \cdot$ Shouzheng Tang ${ }^{1}$. \\ Peter Marshall ${ }^{4} \cdot$ Lin Cao $^{5} \cdot$ Xinyu Song ${ }^{1,6} \cdot \mathrm{Li} \mathrm{Yu}^{1} \cdot$ Jingjing Liang ${ }^{7}$
}

Received: 14 September 2016 / Accepted: 11 April 2017 /Published online: 15 May 2017

(C) INRA and Springer-Verlag France 2017

\begin{abstract}
- Key message A climate-sensitive aboveground biomass (AGB) equation, in combination with nonlinear mixedeffects modeling and dummy variable approach, was developed to examine how climate change may affect the allometric relationships between tree diameter and biomass. We showed that such changes in allometry need to be taken into account for estimating tree AGB in Masson pine.

- Context As a native species and being widely distributed in subtropical China, Masson pine (Pinus massoniana Lamb.) forests play a pivotal role in maintaining forest ecosystem functions and mitigation of carbon concentration increase at
\end{abstract}

\section{Handling Editor: Shuqing Zhao}

Contribution of the co-authors $\mathrm{L}$. Fu was the principal investigator for this study. He undertook the main data analyses and wrote the manuscript. $X$. Lei supervised the research project and contributed to interpretation of results and the writing and revision of earlier drafts until final approval. W. Zeng, S. Tang, P. Marshall, L. Cao, X. Song, and J. Liang contributed to the presentation of the statistical results and interpretations of the results and revised the text. L. Yu and Z. Hu. contributed to climate data preparation.

Electronic supplementary material The online version of this article (doi:10.1007/s13595-017-0636-z) contains supplementary material, which is available to authorized users.

Xiangdong Lei

xdlei@ifrit.ac.cn

1 Research Institute of Forest Resource Information Techniques, Chinese Academy of Forestry, Beijing 100091, People's Republic of China

2 College of Resources, Sichuan Agricultural University, Chengdu 611130, Sichuan Province, People's Republic of China

3 Academy of Forest Inventory and Planning, State Forestry Administration, Beijing 100714, People's Republic of China the atmosphere. Traditional biomass allometric equations do not account for a potential effect of climate on the diameterbiomass relationships. The amplitude of such an effect remains poorly documented.

- Aims We presented a novel method for detecting the longterm (2041-2080) effects of climate change on the diameterbiomass relationships and the potential consequences for long-term changes of biomass accumulation for Masson pine. - Methods Our approach was based on a climate-sensitive AGB model developed using a combined nonlinear mixedeffects model and dummy variable approach. Various climaterelated variables were evaluated for their contributions to model improvement. Heteroscedasticity was accounted for by three residual variance functions: exponential function, power function, and constant plus function.

- Results The results showed that diameter at breast height, together with the long-term average of growing season temperature, total growing season precipitation, mean temperature of wettest quarter, and precipitation of wettest quarter, had significant effects on values of AGB. Excessive rain during the growing season and high mean temperature in the wettest quarter reduced the AGB, while a warm growing season and abundant precipitation in the wettest quarter increased the AGB.

4 Department of Forest Resources Management, University of British Columbia, Vancouver, BC V6T 1Z4, Canada

5 Co-Innovation Center for Sustainable Forestry in Southern China, Nanjing Forestry University, 159 Longpan Road, Nanjing 210037, Jiangsu Province, People's Republic of China

6 College of Computer and Information Techniques, Xinyang Normal University, Xinyang 464000, Henan Province, People's Republic of China

7 Division of Forestry and Natural Resources, West Virginia University, Morgantown, WV 26506, USA 
- Conclusion Climate change significantly affected the allometric scale of biomass equation. The new climate-sensitive allometric model developed in this study may improve biomass predictions compared with the traditional model without climate effects. Our findings suggested that the AGB of Masson pine trees with the same diameter at breast height under three climate scenarios including representative concentration pathway (RCP) 2.6, RCP 4.5, and RCP 8.5 in the future period 2041-2080 would increase by $24.8 \pm 32.7 \%$ (mean \pm standard deviation), $27.0 \pm 33.4 \%$, and $27.7 \pm 33.8 \%$ compared with the constant climate (19502000), respectively. As a consequence, we may expect a significant regional variability and uncertainty in biomass estimates under climate change.

Keywords Masson pine $\cdot$ Subtropical China $\cdot$ Climate change $\cdot$ Climate-sensitive aboveground biomass model . Nonlinear mixed-effects model $\cdot$ Dummy variable approach

\section{Introduction}

Global climate change affects all aspects of forest community structure and ecosystem production, such as seedling establishment (Daniels and Veblen 2004), tree growth and mortality (Peng et al. 2011; Subedi and Sharma 2013; Lei et al. 2016), tree species distribution (Hamann and Wang 2006; Sinervo et al. 2010), competition among species (Hamann and Wang 2006; Boisvert-Marsh et al. 2014; Monleon and Lintz 2015), and forest biomass and productivity (Jiang et al. 2015; Tian et al. 2016). Forests play an important role in mitigation of climate change by removing carbon from the atmosphere and storing it in biomass. Consequently, it becomes increasingly important to understand how climate affects forest biomass. The information on the effect of climate on forest biomass can provide valuable insights for formulating forest management strategies, with respect to sustainability and climate change adaptations (Marlon et al. 2008; Lei et al. 2016).

Process-based models have been used to describe climatic effects on forest biomass and productivity for various climatic zones and tree species (Eggers et al. 2008; Shuman and Shugart 2009; Poudel et al. 2011). Not surprisingly, the responses are inconsistent. For the Mediterranean climate zone in Europe, it has been speculated that climate change may increase forest productivity by $12-14 \%$ and carbon stock by $23-31 \%$ in the next 50 years (Eggers et al. 2008). For the Eurasian boreal forests, Shuman and Shugart (2009) found that a significant relationship existed between altered precipitation and biomass. Their analysis also showed that a modest increase in temperature of $2{ }^{\circ} \mathrm{C}$ over 200 years would have no significant effects on biomass. For the temperate continental climate zone in north-central Sweden, an average regional temperature increase of $4{ }^{\circ} \mathrm{C}$ over the next 100 years was suggested to increase annual forest productivity by $33 \%$ and the potential annual harvest by $32 \%$ (Poudel et al. 2011). The temperate moist forests with cool temperatures and moderately high precipitation were found to have the highest biomass and carbon stocks (Keith et al. 2009). For the tropical forests, Stegen et al. (2011) found that aboveground biomass was inversely related to mean annual temperature in wet tropical forest sites and positively related in moist tropical forests and that biomass was positively related to annual precipitation in dry tropical forests. In addition, empirical studies have revealed that rising temperatures increase the availability of soil nitrogen and when combined with a longer growing season, it is expected to increase overall tree growth/biomass (Strömgren and Linder 2002). However, on some sites, increasing temperature may result in temperature-induced drought stress and thus reduce tree growth/biomass (Wilmking et al. 2004). To our knowledge, the magnitude of climate effects on forest biomass remains poorly characterized for the subtropical forests. Traditional biomass allometric equations do not account for a potential climate-biomass relationship and may produce bias for biomass and carbon estimation (Xiang et al. 2011; Zeng et al. 2011; Fu et al. 2016).

The subtropical climate zone in China is located in the eastern part of the country between latitudes $22^{\circ}$ and $34^{\circ} \mathrm{N}$ and longitudes $98^{\circ}$ and $123^{\circ} \mathrm{E}$ (Yang et al. 2006). Its climate is characterized by hot, humid summers and chilly winters (Yang et al. 2006). The subtropical area in China is stratified into three different secondary climate zones (north-, middle-, and southsubtropical zones) based on the mean air temperature and the number of days without frost (Huang 1992). This zone accounts for $63 \%$ of the total plantation area (SFA 2012) and about 25\% of the total forest biomass in China (Lin et al. 2012). China's subtropical forests, which include Masson pine (Pinus massoniana Lamb.) and Chinese fir (Cunninghamia lanceolata Lamb. Hook) dominated stands, supply about two thirds of the harvested roundwoods, and are crucial to the economic and social development of rural populations, as well as regional carbon storage and cycling (SFA 2012). Masson pine dominates the regional forests and plays an important role in maintaining the structure and functions of the forest ecosystems in the entire subtropical zone. Masson pine covers a total of 1.13 million ha of forested land, spread throughout 17 provinces in China. Owing to its wide distribution and ability to grow in poor site conditions and regenerate naturally, as well 
as its rapid growth rate, Masson pine can greatly contribute to carbon sequestration and storage. Several individual tree biomass models have been developed to estimate the biomass and carbon storage of Masson pine in the subtropical China (Xiang et al. 2011; Zeng et al. 2011; Fu et al. 2016); however, these models did not consider the effects of climate change on biomass allometry.

The limited knowledge of how changes in the regional climate affect the biomass of Masson pine in the subtropical China makes it challenging to prepare for the potential consequences of climate change. According to the Abdus Salam International Centre for Theoretical Physics (ICTP) Regional Climate Model version 3 (RegCM3) with the A1B scenario (IPPC 2001), the mean temperatures in the periods of December-JanuaryFebruary (DJF) and June-July-August (JJA) in China are expected to rise by 5.5 and $5.0^{\circ} \mathrm{C}$, respectively, by the end of the twenty-first century (Gao et al. 2012). Therefore, the objectives of this study were (1) to develop an individual climate-sensitive aboveground biomass (AGB) model with Masson pine as a case study and (2) to examine how climate change may affect the allometric relationships between diameter and biomass and assess the potential error in predicting AGB of Masson pine under different climate scenarios based on the developed AGB model.

\section{Materials and methods}

\subsection{Biomass data}

The biomass data used in this study were collected according to the protocol of data collection for tree biomass modeling which was drafted by the State Forestry Administration of China (SFA 2014). A total of 150 Masson pine trees from both natural and planted forests in subtropical China were destructively sampled in 2009 (Fig. 1). The sample trees were located in a broad area in which various forests of Masson pine were distributed and covered nine provinces (Jiangsu, Zhejiang, Anhui, Fujian, Jiangxi, Hunan, Guangdong, Guizhou, and Guangxi) randomly selected from the 16 provinces in this region (Fig. 1). The number of the trees sampled in each province was determined depending on the provincial area, stand origin, and diameter at breast height $(D)$ class in proportion to its contribution to the total stocking volume of the species in the entire region. The number of the sample trees allocated to natural and planted forests was also determined on a pro rata basis with 77 trees selected from the former and 73 trees from the latter. The sample trees were distributed evenly among $D$ classes of $2,4,6,8,12$, $16,20,26,32$, and $\geq 38 \mathrm{~cm}$ (i.e., 15 trees for each $D$ class, except for the 26 and $32 \mathrm{~cm}$ classes in which there were 14 and 16 trees, respectively). Additionally, the sample trees in each $D$ class were classified, as evenly as possible, into three to five height classes, with three to five trees in each height class. The sample trees represented the characteristics of forests in each secondary climate zone in subtropical China. Their percentages among the $D$ classes and climate zones (north-, middle-, and south-subtropical zones and the entire subtropical zone) are shown in Fig. 2a, b, respectively.

The diameter at breast height $(D)$ was measured on each standing sample tree in the field. After a tree was felled, the total tree length, the length of its living crown, and the diameter at ground level were also measured. The fresh masses of stem wood, stem bark, branch, and foliage were weighted, and all the subsamples (stem sections of a sample tree) were selected and weighed in the field for water content analysis. After being taken to the laboratory, all the subsamples were oven-dried at $85{ }^{\circ} \mathrm{C}$ until a constant dry weight was reached. Using the dry weight to fresh weight ratio, the biomass of each component (wood, bark, branch, and foliage) was calculated and added together to get the total AGB of each tree. The relationship of AGB with $D$ for each climate zone with stand origin (natural and planted) is shown in Fig. 2c.

The complete biomass dataset was randomly divided into two groups: 120 trees for model calibration (calibration dataset) and the other 30 trees for model validation (validation dataset). The data and relevant stand characteristics for the calibration and validation datasets are summarized in Table 1.

\subsection{Climate data}

Climate data for the subtropical China were obtained from the WorldClim database (http://www.worldclim.org) with 18 candidate bioclimatic variables (Table OR 1 in supplementary file) at a $1 \mathrm{~km} \times 1 \mathrm{~km}$ spatial resolution (Hijmans et al. 2005). The growing season was determined using temperature-based rules, starting when the mean daily temperature was greater than $6.0^{\circ} \mathrm{C}$ for five consecutive days, and ending when the average temperature fell below $10.5^{\circ} \mathrm{C}$ after the first day of August (Feng et al. 2011). The observations of the variables were averaged for the period 1950-2000. 


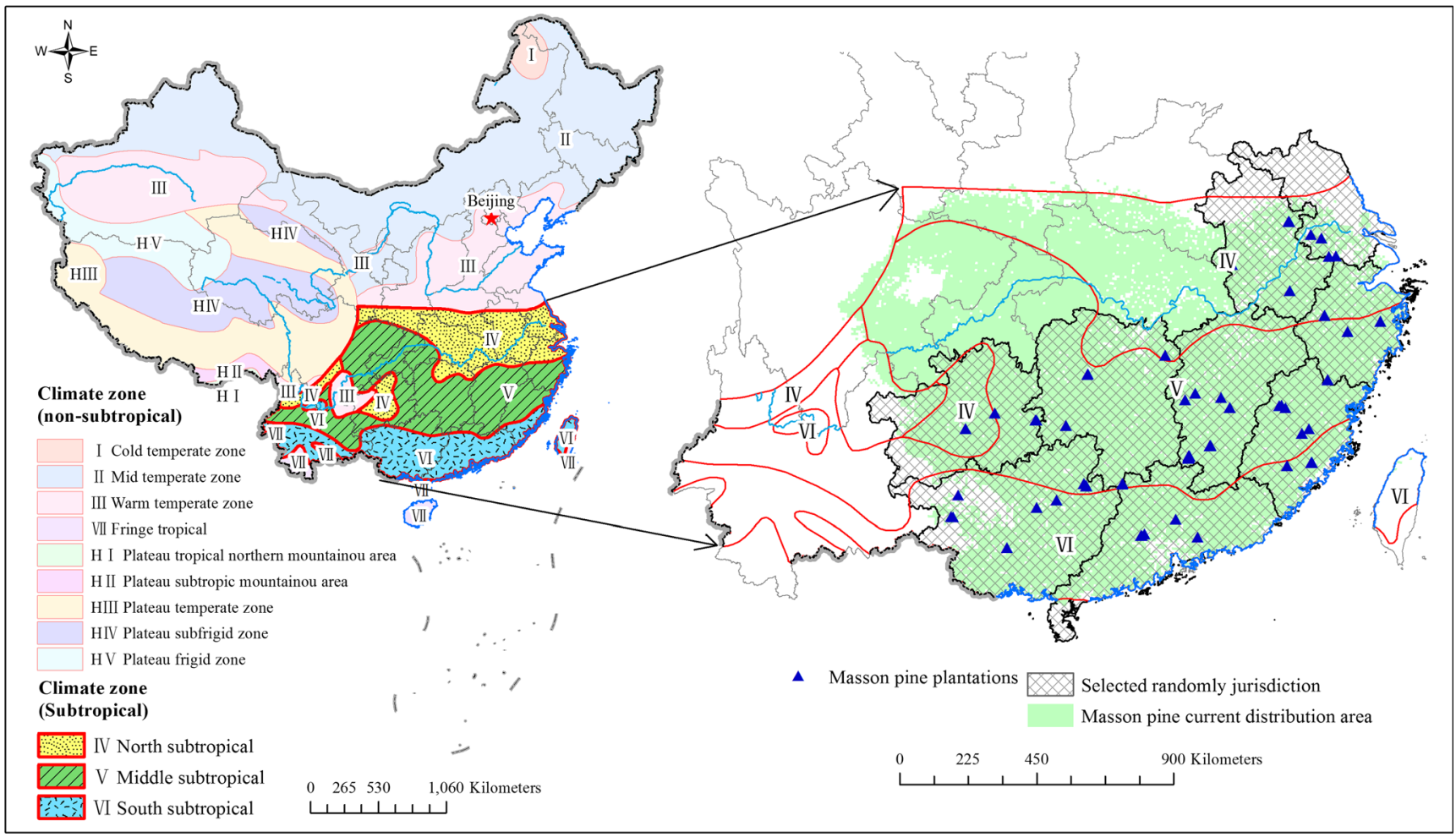

Fig. 1 Distribution of Masson pine sample sites across the subtropical China. The distribution of Masson pine forests in China can be divided into four subregions, namely, the north-subtropical, middle-subtropical, south-subtropical, and other climate zones (such as mid-temperate zone). However, the fourth subregion had less than $1 \%$ of the stand volume of Masson pine in China and was thus not included in this study (SFA 2012)

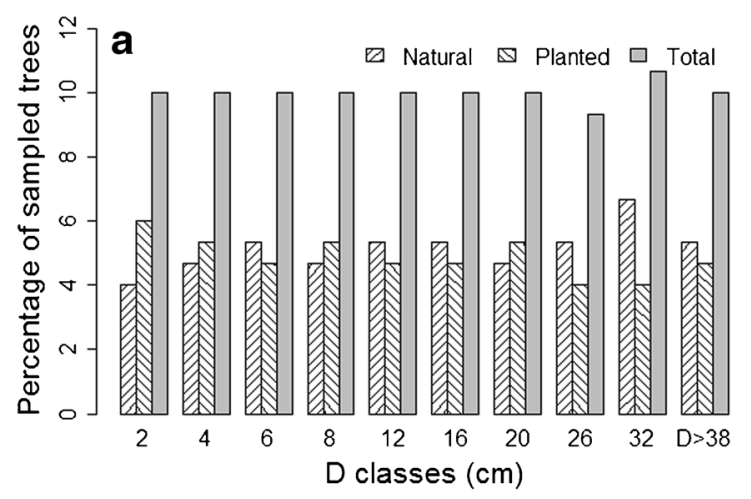

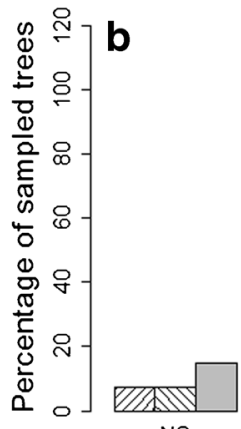

NS
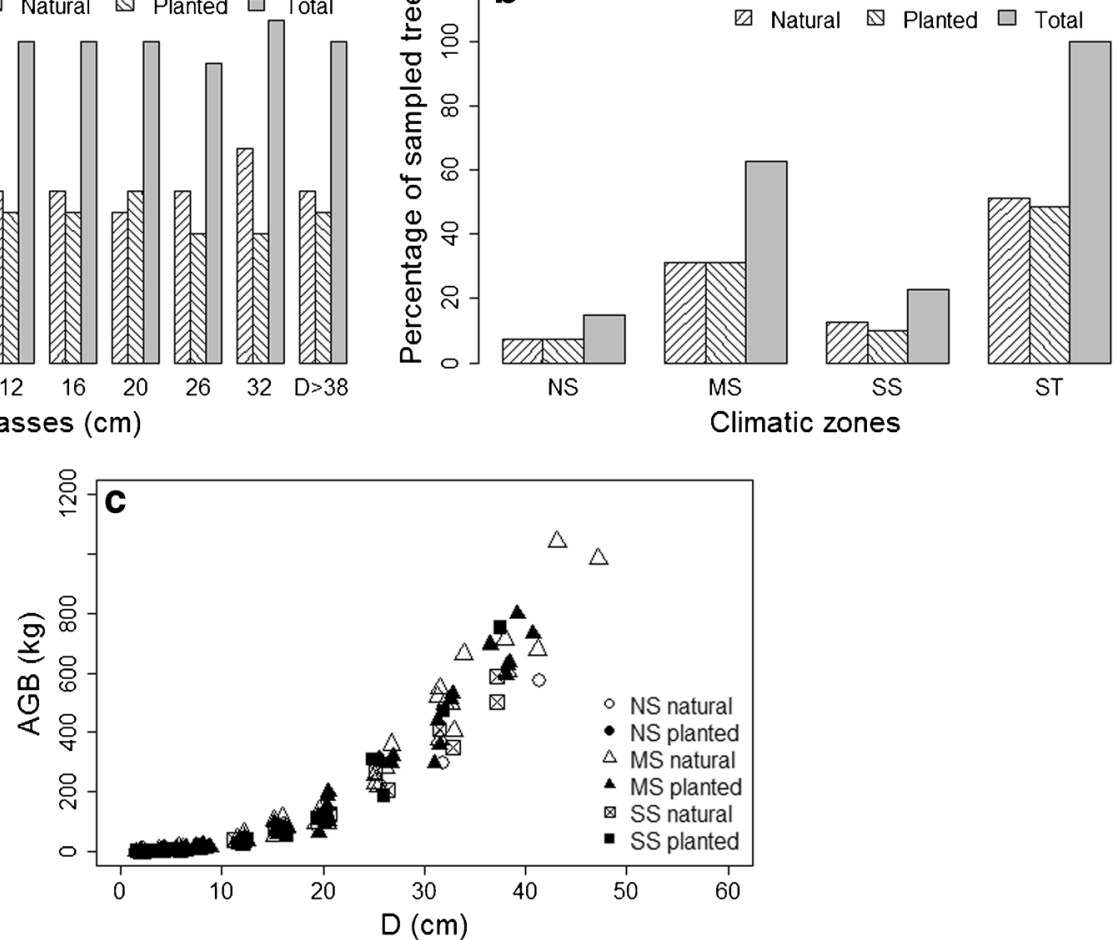

Fig. 2 The percentages of the sampled trees falling. a Diameter at breast height $(D, \mathrm{~cm})$ classes. b Climate zones including the north-, middle-, and south-subtropical zones and the entire subtropical zone (denoted by NS,

$M S, S S$, and $S T$, respectively). c The relationship of aboveground biomass $(A G B, \mathrm{~kg})$ with $D$ for different stand origins with natural and planted forests 
Table 1 Summary statistics of diameter at breast height $(D)$ and total aboveground biomass (AGB) of Masson pine by origins (natural and planted forests) and secondary climate zones for model calibration and validation datasets used in this study (N denotes the total number of observations, and SD denotes the standard deviation)

\begin{tabular}{|c|c|c|c|c|c|c|c|c|c|c|}
\hline \multirow[t]{2}{*}{ Variable } & \multicolumn{5}{|c|}{ Calibration data } & \multicolumn{5}{|c|}{ Validation data } \\
\hline & $N$ & Mean & SD & Min & Max & $N$ & Mean & SD & Min & Max \\
\hline \multicolumn{11}{|l|}{ Natural } \\
\hline$D(\mathrm{~cm})$ & 62 & 17.38 & 12.24 & 2.00 & 43.10 & 15 & 18.45 & 13.61 & 2.00 & 47.20 \\
\hline AGB (kg) & 62 & 178.16 & 233.07 & 0.54 & 1039.14 & 15 & 213.35 & 295.64 & 0.59 & 981.78 \\
\hline \multicolumn{11}{|l|}{ Planted } \\
\hline$D(\mathrm{~cm})$ & 58 & 15.48 & 11.36 & 1.50 & 40.70 & 15 & 15.48 & 13.62 & 2.10 & 39.20 \\
\hline AGB (kg) & 58 & 146.42 & 209.30 & 0.32 & 751.94 & 15 & 175.08 & 272.75 & 0.75 & 797.05 \\
\hline \multicolumn{11}{|c|}{ North-subtropical } \\
\hline$D(\mathrm{~cm})$ & 19 & 11.84 & 11.01 & 1.60 & 41.40 & 3 & 10.07 & 5.42 & 5.90 & 16.20 \\
\hline AGB (kg) & 19 & 77.14 & 144.87 & 0.54 & 575.09 & 3 & 34.37 & 43.09 & 4.08 & 83.71 \\
\hline \multicolumn{11}{|c|}{ Middle-subtropical } \\
\hline$D(\mathrm{~cm})$ & 73 & 17.82 & 11.62 & 1.50 & 43.10 & 21 & 19.13 & 15.04 & 2.00 & 47.20 \\
\hline AGB (kg) & 73 & 188.48 & 237.14 & 0.38 & 1039.14 & 21 & 250.65 & 315.57 & 0.59 & 981.78 \\
\hline \multicolumn{11}{|c|}{ South-subtropical } \\
\hline$D(\mathrm{~cm})$ & 28 & 16.06 & 12.41 & 1.70 & 37.50 & 6 & 12.83 & 8.18 & 5.90 & 25.20 \\
\hline AGB (kg) & 28 & 154.07 & 212.94 & 0.32 & 751.94 & 6 & 76.62 & 104.13 & 4.91 & 268.05 \\
\hline \multicolumn{11}{|l|}{ Total } \\
\hline$D(\mathrm{~cm})$ & 120 & 16.47 & 11.81 & 1.50 & 43.10 & 30 & 16.96 & 13.47 & 2.00 & 47.20 \\
\hline AGB (kg) & 120 & 162.82 & 221.54 & 0.32 & 1039.14 & 30 & 194.22 & 280.16 & 0.59 & 981.78 \\
\hline
\end{tabular}

\subsection{Climate-sensitive aboveground biomass model}

Allometric models are most commonly used to estimate tree biomass by relating tree biomass to easily measured variables (e.g., D) (Zeng et al. 2011; Chave 2014). Zeng et al. (2011) developed an allometric model (model 1) for Masson pine AGB estimation based on $D$, coupled with a dummy variable approach to address tree origins. They reported that their AGB model provided higher predictive accuracy than other Masson pine AGB models tested. We selected model (1) as the base function to develop our AGB models in this study.

$\mathrm{AGB}=\exp \left(\beta_{0}+L \times S\right) D^{\beta_{1}}+\varepsilon$

where AGB is the aboveground biomass $(\mathrm{kg}) ; D$ is the diameter at breast height $(\mathrm{cm}) ; S$ is a dummy variable representing the stand origins, which takes a value 1 for plantations and 0 for natural forests; $\beta_{0}, \beta_{1}$, and $L$ are model coefficients; and $\varepsilon$ is the error term.

The allometric scaling theory suggests the existence of a universal power-law relationship between tree biomass and $D$ with a fixed allometric power (e.g., close to 8/3) which has been verified by numerous studies for various tree species in geographically and ecologically different regions around the world (West et al. 1997, 1999; Vieilledent et al. 2012; Anitha et al. 2015). Therefore, in this study, it was assumed that climate would only affect the allometric scale, that is, intercept term $\beta_{0}$ in model (1) in the allometric model. The parameter was modified by the subtropical zone-related dummy variables and climatic variables. Firstly, we introduced two additional dummy variables, $T_{1}$ and $T_{2}$, to represent differences among three secondary climate zones in the subtropical China: $T_{1}=1$ and $T_{2}=0$ denoted the south-subtropical zone; $T_{1}=0$ and $T_{2}=1$ the middle-subtropical zone; and $T_{1}=0$ and $T_{2}=0$ the north-subtropical zone. Then, the AGB model took the following form

$\mathrm{AGB}=\exp \left(\beta_{0}+L \times S+k_{1} T_{1}+k_{2} T_{2}\right) D^{\beta_{1}}+\varepsilon$

where $k_{1}$ and $k_{2}$ were the model coefficients, and the other variables were defined as above for model (1).

To explicitly include climatic variables, we modified model (2) by incorporating the temperature- and precipitation-related variables described previously. Model (2) was first fitted to the calibration dataset for Masson pine using generalized leastsquares (GLS) in R (R Development Core Team 2011). Then, a combination of temperature- and precipitation-related variables was introduced to the model and evaluated for their contributions to model improvement. The climate variables that 
Table 2 Parameter estimates and fit statistics (standard error (SE), Akaike's Information Criterion (AIC), logarithm likelihood (loglikelihood)) of models (2) and (3) using generalized least-squares, and model (7) using a nonlinear mixed-effects model approach for Masson pine data from the subtropical China $\left(\beta_{0}-\beta_{5}, k_{1}, k_{2}\right.$, and $L$ are the model coefficients; $\sigma^{2}$ is the scaling factor of the error dispersion; and $u_{3}$ and $u_{5}$ represent the random-effect coefficients)

\begin{tabular}{|c|c|c|c|c|c|c|}
\hline \multirow[t]{2}{*}{ Parameters } & \multicolumn{2}{|l|}{ Model (2) } & \multicolumn{2}{|l|}{ Model (3) } & \multicolumn{2}{|l|}{ Model (7) } \\
\hline & Estimates & SE & Estimates & SE & Estimates & SE \\
\hline$\beta_{0}$ & -2.9435 & 0.2809 & -2.7271 & 1.3385 & -1.4544 & 2.2098 \\
\hline$k_{1}$ & 0.2876 & 0.0680 & -0.0285 & 0.1079 & -0.0175 & 0.1237 \\
\hline$k_{2}$ & 0.3821 & 0.0632 & 0.0077 & 0.1069 & 0.0767 & 0.0819 \\
\hline$L$ & -0.0031 & 0.0292 & 0.0240 & 0.0272 & -0.0285 & 0.0471 \\
\hline$\beta_{1}$ & 2.5037 & 0.0760 & 2.4715 & 0.0683 & 2.3697 & 0.0296 \\
\hline$\beta_{2}$ & & & -0.9078 & 0.4667 & -0.7053 & 0.5677 \\
\hline$\beta_{3}$ & & & 1.1108 & 0.4566 & 0.7337 & 0.4842 \\
\hline$\beta_{4}$ & & & -1.1991 & 0.3104 & -0.3961 & 0.3679 \\
\hline$\beta_{5}$ & & & 1.0760 & 0.4030 & 0.4973 & 0.5346 \\
\hline \multicolumn{7}{|c|}{ Variance components } \\
\hline$\sigma^{2}$ & 0.5792 & & 0.4380 & & 0.0450 & \\
\hline $\operatorname{var}\left(u_{3}\right)$ & & & & & 0.0001 & \\
\hline $\operatorname{var}\left(u_{5}\right)$ & & & & & 0.00003 & \\
\hline $\operatorname{cov}\left(u_{3}, u_{5}\right)$ & & & & & 0.00001 & \\
\hline \multicolumn{7}{|c|}{ Autocorrelation structure } \\
\hline$\rho$ & & & & & 0.1412 & \\
\hline \multicolumn{7}{|c|}{ Weight (power of $D$ ) } \\
\hline$\gamma$ & & & & & 2.1463 & \\
\hline AIC & 1241.4790 & & 1214.1370 & & 889.7032 & \\
\hline Log-likelihood & -614.7396 & & -597.0685 & & -429.8516 & \\
\hline
\end{tabular}

were both significant $(\alpha=0.05)$ and improved model fitting were selected. During the variable selection, we prioritized choosing a set of variables with minimum multicollinearity assessed using the variance inflation factor.

The evaluation of combining the temperature- and precipitation-related variables indicated that the total growing season precipitation (TGSP), mean growing season temperature (MGST), mean temperature of wettest quarter (MTWQ), and precipitation of wettest quarter (PWQ) were significant in explaining variations in the AGB of Masson pine $(p<0.05)$ (Table 2). The spatial distributions of the four climate variables for the period 1950-2000 are displayed in Fig. 3. After the variables were involved, the model (hereafter referred to as the full model) was as follows

$$
\begin{aligned}
A G B= & \exp \left(\beta_{0}+L \times S+k_{1} T_{1}+k_{2} T_{2}\right) D^{\beta_{1}} T G S P^{\beta_{\mathcal{q}}} \\
& M G S T^{\beta_{3}} M T W Q^{\beta_{4}} P W Q^{\beta_{5}}+\varepsilon
\end{aligned}
$$

where $\beta_{0}-\beta_{5}, k_{1}, L$, and $L$ are the model coefficients, and the other variables were as defined previously.
When the long-term averages of the four climate variables were included, Akaike's information criterion (AIC) and the logarithm of the likelihood function (log-likelihood) indicated that the model fitness was improved (Table 2).

\subsection{Model calibration and evaluation}

When the relationship of tree AGB with stand or tree variables are modeled, the measurements of tree variables are often collected from trees growing in sample plots located in different stands with different regions. This hierarchical structure (i.e., trees within regions) can lead to dependence among the measurements, as the observations from the same sampling unit (i.e., each province in this study) are likely to be significantly correlated (i.e., autocorrelation likely exists) (Pinheiro and Bates 2000). To address the problem of autocorrelation, nonlinear mixed-effects modeling (e.g., Fu et al. 2014a, 2014b), recognition of the correlation structure (e.g., DiéguezAranda et al. 2006), or both (e.g., Trincado and 
Fig. 3 Surface maps of average mean growing season temperature $(M G T)(\mathbf{a})$, average mean temperature of wettest quarter $(T W Q)(\mathbf{b})$, average total growing season precipitation $(T G P)(\mathbf{c})$, and average precipitation of wettest quarter $(P W Q)(\mathbf{d})$ for the period from 1950 to 2000 in three secondary climate zones (north-, middle-, and south-subtropical) in the subtropical China
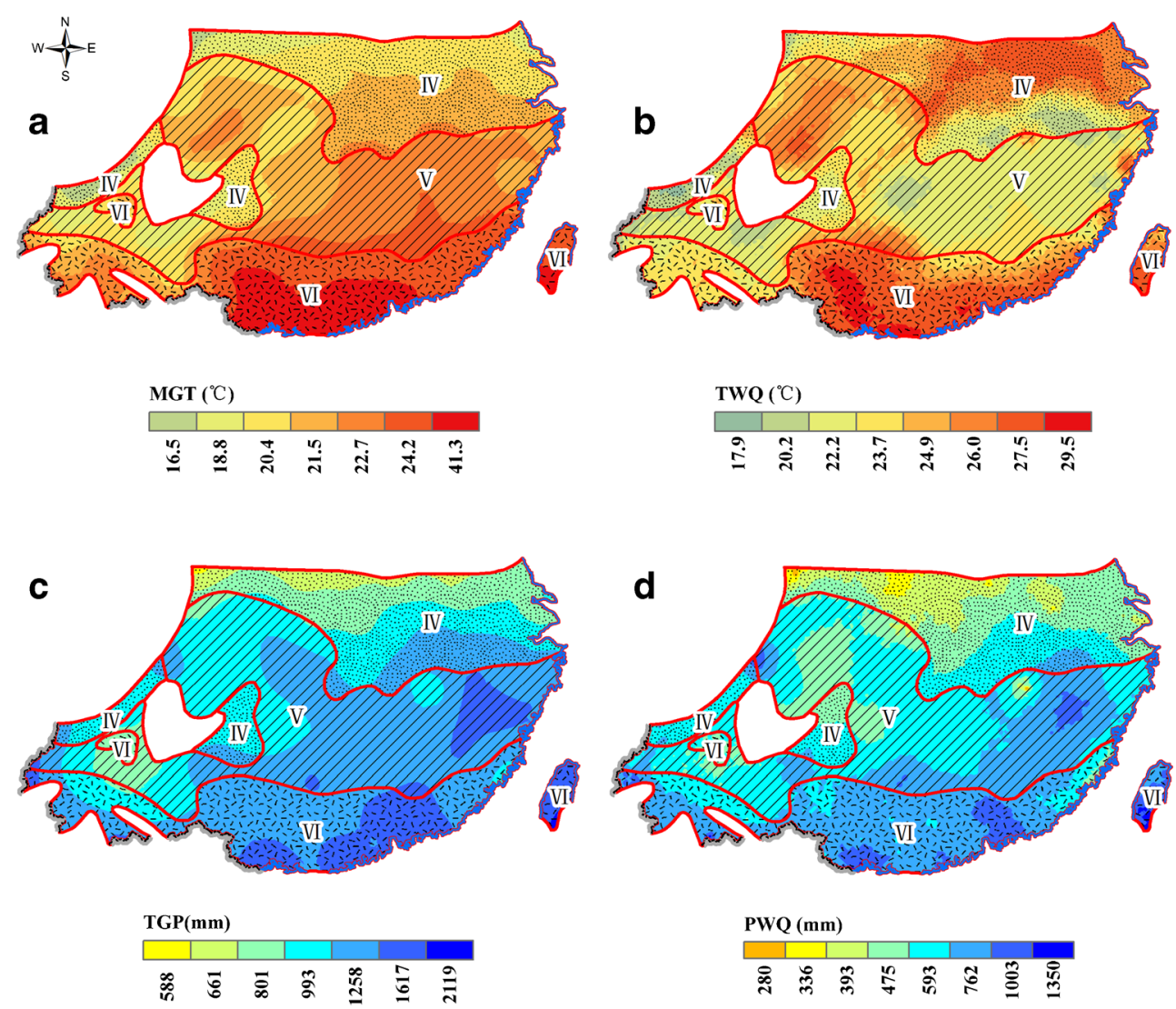

Climate zone

(Subtropical)

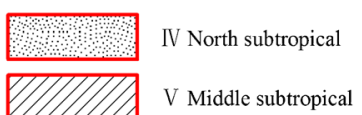

VI South subtropical

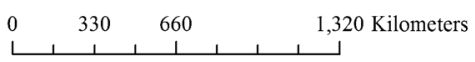

Middle subtropical

Burkhart 2006) have been used. We chose to use the nonlinear mixed-effects modeling approach provided in the SPlus nlme function (Pinheiro and Bates 2000) to develop the full model. Random-effect parameters were added sequentially, starting with one coefficient as a random effect.

The residuals of the AGB prediction model with random grouping (i.e., province) effects were analyzed for possible autocorrelation or heteroscedasticity. To account for withinprovince autocorrelation and heteroscedasticity in the variance-covariance matrix $\left(\mathbf{R}_{i}\right)$ of the error term $\left(\varepsilon_{i}\right)$ (the subscript $i$ denotes the $i^{\text {th }}$ province, $\left.i=1, \ldots, 9\right)$, the approach of Davidian and Giltinan (1995) was used

$\mathbf{R}_{\mathbf{i}}=\sigma^{2} \mathbf{G}_{\mathbf{i}}^{0.5} \boldsymbol{\Gamma}_{\mathbf{i}} \mathbf{G}_{\mathbf{i}}^{0.5}$

where $\sigma^{2}$ is a scaling factor of the error dispersion, which is equal to the residual variance of the estimated model; $\mathbf{G}_{i}$ is a $n_{i} \times n_{i}$ diagonal matrix of the within-province variances; and $\Gamma_{i}$ is a $n_{i} \times n_{i}$ matrix showing the within-province autocorrelation structure of the errors.

The empirical autocorrelation function (ACF) for model (3) indicated that the autocorrelation was significant $(\alpha=0.05)$ among the residuals within the provinces (Fig. 4a). As a result, the final model was estimated as a nonlinear mixed-effects model, accounting for the withinprovince autocorrelation. The autocorrelation structure autoregressive process of order one (AR (1)) for matrix $\boldsymbol{\Gamma}_{i}$ was applied in this study.

Preliminary analysis for fitting model (3) showed clear evidence of heteroscedasticity in our datasets (Fig. 5a). Some heteroscedasticity remained even after incorporating the autocorrelation structure in the nonlinear mixed-effects model. The heteroscedasticity was removed by specifying a withinprovince variance function (Pinheiro and Bates 2000). Three common variance functions, e.g., the exponential function $\left[\operatorname{var}\left(\varepsilon_{i j}\right)=\sigma^{2} \exp \left(2 \gamma D_{i j}\right)\right]$, the power function 
Fig. 4 Empirical autocorrelation function (ACF) corresponding to the standardized residuals of the Masson pine biomass data for model (3) (a) and model (7) b with an autoregressive process of order one (AR (1)) autocorrelation structure $(\alpha=0.05)$
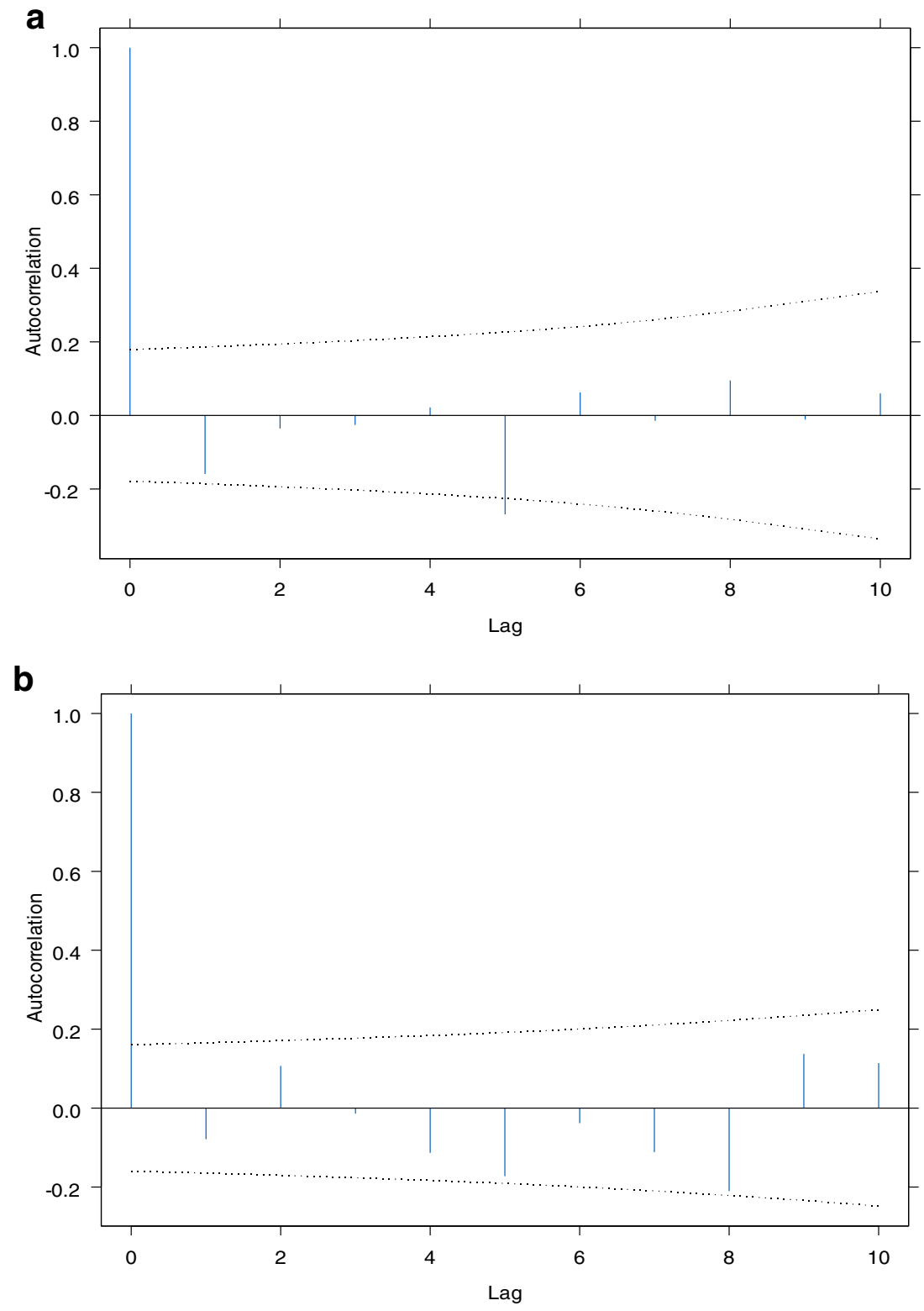

$\left[\operatorname{var}\left(\varepsilon_{i j}\right)=\sigma^{2}\left|D_{i j}\right|^{2 \gamma}\right]$, and the constant plus power function $\left[\operatorname{var}\left(\varepsilon_{i j}\right)=\sigma^{2}\left(\gamma_{1}+D_{i j}^{\gamma_{2}}\right)^{2}\right]$ were evaluated, where $D_{i j}$ is the diameter at breast height of the $j$ th tree in the $i$ th province, and $\gamma, \gamma_{1}, \gamma_{2}$ and $\gamma_{3}$ are estimated parameters (Pinheiro and Bates 2000). The function that gave the best fit (e.g., the smaller AIC) and provided the smallest residuals with better behavior was selected. The coefficients of the final model were estimated using the restricted maximum likelihood method (Pinheiro and Bates 2000).

We assessed the accuracy of our AGB model using both the calibration and validation datasets in Table 1 based on the mean bias $\bar{e}$ (observed AGB - predicted AGB), the variance of residuals $(v)$, and the root mean square error (RMSE)
$\left(\mathrm{RMSE}=\sqrt{\bar{e}^{2}+v}\right)$. RMSE, which combines the mean bias and the variation of the residuals, was used as the primary criterion for AGB model evaluations.

\subsection{Potential effects of changing allometry on tree biomass estimates under future climate scenarios}

Model (3) was applied to predict the future AGB of Masson pine trees with the same dataset (Table 1) on each sampled site under future climate scenarios in the three secondary climate zones of subtropical China. The relative difference $\left(R_{\mathrm{AGB}}\right)$ in AGB between current and future climate scenarios was derived (Eq. (5)). For avoiding the uncertainties from $D$ predictions in the future 

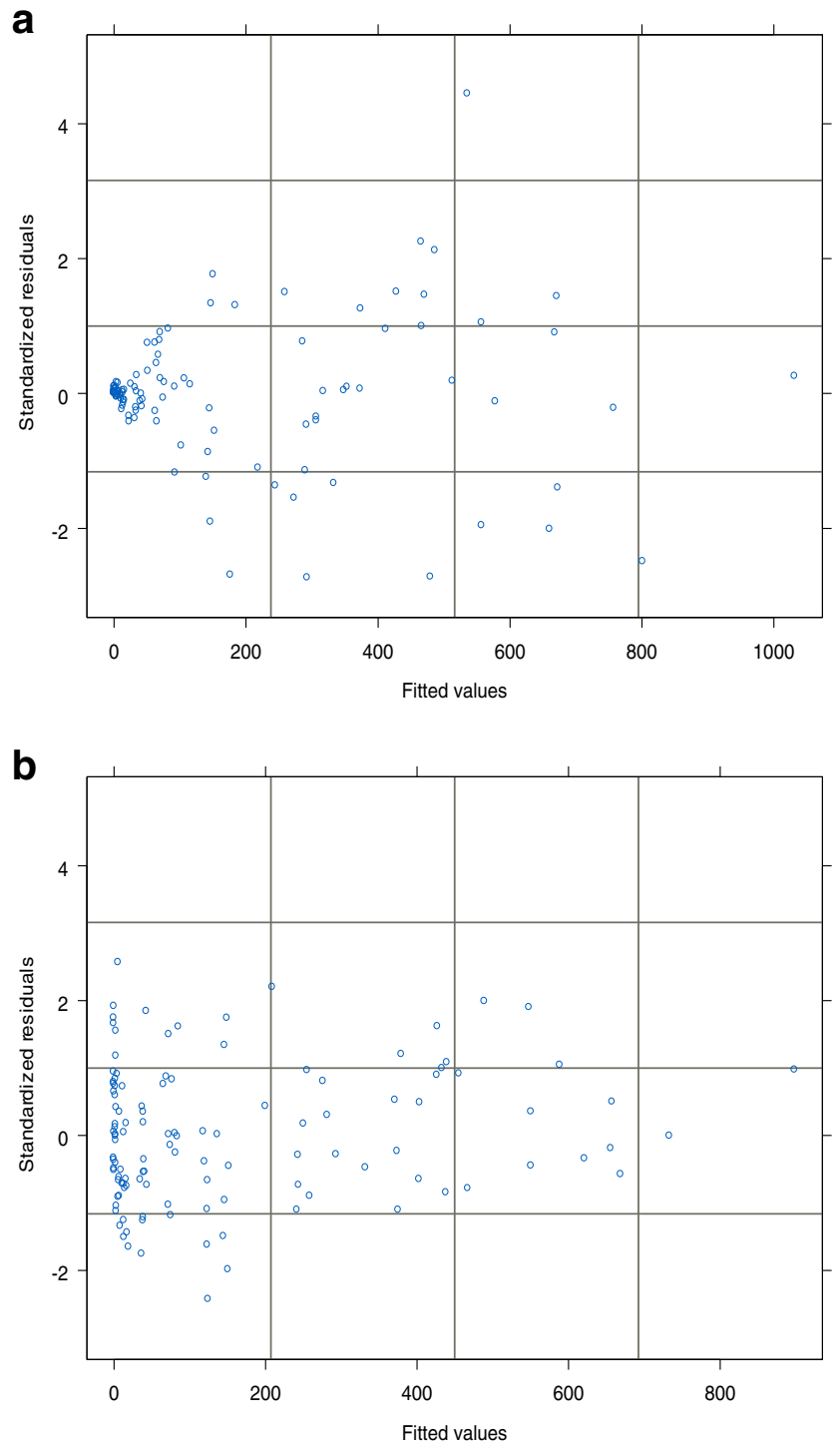

Fig. 5 Distribution of standard residuals for model (3) (a) and model (7) (b) predictions of the aboveground biomass of Masson pine trees in the subtropical China

and making reasonable comparisons, the $D$ values (that is, observed values) of the sample trees were considered constant and applied for estimating the future AGB of Masson pine tree under each climate change scenario. Thus, the effects of different climate scenarios in the future on AGB variation in the different climate zones (e.g., north-, middle-, and south-subtropical zones and the entire subtropical zone) were evaluated under the constraint of the same $D$. We used the latest climate change scenarios of the fifth Assessment Report from the IPCC based on a downscaled global climate model (GCM) applied in three
Table 3 Performance assessment of nonlinear mixed-effects model (6) using the Masson pine biomass data with autocorrelation structure autoregressive process of order one (AR (1)) and three variance functions (exponential function, power function, and constant plus power function), respectively (AIC denotes the Akaike information criterion; Log-likelihood denotes the logarithm likelihood; and variance function 1 means that the variances are homogeneous)

\begin{tabular}{lcl}
\hline Type & AIC & Log-likelihood \\
\hline Autocorrelation structure AR (1) & 889.7032 & -429.8516 \\
Variance functions & & \\
$\quad$ Exponential function & 956.9301 & -464.465 \\
Power function & 889.5079 & -430.7540 \\
Constant plus power function & 890.9463 & -430.7732 \\
1 & 1193.8790 & -583.9392 \\
\hline
\end{tabular}

representative concentration pathways (RCPs): RCP 2.6, RCP 4.5, and RCP 8.5 (IPCC 2013). The scenarios indicated low, medium, and high concentrations of greenhouse gases and predictive radiative forcing. The GCM was Beijing Climate Center Climate System Model (BCC-CSM1-1) developed in China. The future climate data at a spatial resolution of $1 \mathrm{~km} \times 1 \mathrm{~km}$ for the two periods 2041-2060 and 2061-2080 were downloaded from the WorldClim dataset (Hijmans et al. 2005).

$R_{\mathrm{AGB}}=\frac{\mathrm{AGB}_{f \mid D}-\mathrm{AGB}_{c \mid D}}{\mathrm{AGB}_{c \mid D}} \times 100 \%$

where $R_{\mathrm{AGB}}$ is the relative difference in $\mathrm{AGB}$ between current and future climate scenarios, and $\mathrm{AGB}_{c \mid D}$ and $\mathrm{AGB}_{f \mid D}$ are the observed and estimated AGB with the same $D$ under the current and future scenarios, respectively.

\section{Results}

\subsection{Climate-sensitive aboveground biomass model}

Considering nine model parameters $\left(\beta_{0}-\beta_{5}, L, k_{1}\right.$, and $\left.k_{2}\right)$ involved, a total of 512 different combinations of the random effects at the province level were obtained for the full model (model (3)). Among these nonlinear mixed-effects model alternatives, only 45 models converged with meaningful parameter estimates. The following nonlinear mixed-effects AGB model (6) showed the smallest AIC (AIC $=1193.88)$ and the largest log-likelihood (log-likelihood $=-583.94$ ) among the models that converged

$A G B_{i j}=\left[\exp \left(\beta_{0}+L \times S+k_{1} T_{1}+k_{2} T_{2}\right) \operatorname{TGSP}_{i j}^{\beta_{2}} \operatorname{MGST}_{i j}^{\left(\beta_{3}+u_{3 i}\right)} \operatorname{MTWQ}_{i j}^{\beta_{4}} P W Q_{i j}^{\left(\beta_{5}+u_{5 i}\right)}\right] D_{i j}^{\beta_{1}}+\varepsilon_{i j}$ 
where $\mathrm{AGB}_{i j}$ is the aboveground biomass of the $j$ th tree in the $i$ th province $\left(j=1, \ldots, n_{i} ; i=1, \ldots, 9\right) ; n_{i}$ is the total observations in the $i$ th province; $\mathrm{TGSP}_{i j}, \mathrm{MGST}_{i j}, \mathrm{MTWQ}_{i j}$, and $\mathrm{PWQ}_{i j}$ are the total growing season precipitation (mm), mean growing season temperature $\left({ }^{\circ} \mathrm{C}\right)$, mean temperature of wettest quarter $\left({ }^{\circ} \mathrm{C}\right)$, and precipitation of wettest quarter $(\mathrm{mm})$ for the $j$ th tree in the $i$ th province, respectively; and $\varepsilon_{i j}$ is the estimation error for the $j$ th tree in the $i$ th province. $u_{3 i}$ and $u_{5 i}$ represent the random-effect coefficients generated for the $i$ th province, and other variables and parameters were as defined previously.

The evaluation indices of autocorrelation structure AR (1) and three variance functions applied to model (6), respectively, are listed in Table 3. For comparison purpose, the assessment results of model (6), in which the variances of error terms were assumed to be homogeneous (i.e., when $\mathbf{G}_{\mathbf{i}}$ and $\boldsymbol{\Gamma}_{\mathbf{i}}$ are identity matrices), were also given (Table 3 ). The AIC and log-likelihood of model (6) with AR (1) were $25.48 \%$ smaller and $26.39 \%$ larger than those of model (6) with homogeneous assumption, respectively, which indicated that the within-province autocorrelation in the Masson pine biomass data could be successfully removed by the AR (1). The power variance function demonstrated the best performance among the variance functions we examined. Therefore, model (6) was fitted with an AR (1) autocorrelation structure and a power variance function of $D$. The final nonlinear mixed-effects AGB model was as follows

$$
\left\{\begin{array}{l}
A G B_{i j}=\left[\exp \left(\beta_{0}+L \times S+k_{1} T_{1}+k_{2} T_{2}\right) \operatorname{TGSP}_{i j}^{\beta_{2}} \operatorname{MGST}_{i j}^{\left(\beta_{3}+u_{3 i}\right)} \mathrm{MTWQ}_{i j}^{\beta_{4}} P W Q_{i j}^{\left(\beta_{5}+u_{5 i}\right)}\right] D_{i j}^{\beta_{1}}+\varepsilon_{i j} \\
\boldsymbol{\varepsilon}_{i}=\left(\varepsilon_{i 1}, \ldots, \varepsilon_{\mathrm{in}_{i}}\right)^{T} \sim N\left(0, \mathbf{R}_{\mathbf{i}}=\sigma^{2} \mathbf{G}_{\mathbf{i}}^{\mathbf{0 . 5}} \boldsymbol{\Gamma}_{\mathbf{i}} \mathbf{G}_{\mathbf{i}}^{\mathbf{0 . 5}}\right) \\
\mathbf{G}_{i}=\operatorname{diag}\left(\left|D_{i 1}{ }^{2 \gamma}\right| \ldots, D_{\mathrm{in}_{i}}{ }^{2 \gamma}\right) \\
\boldsymbol{\Gamma}_{\mathbf{i}} \sim A R(1)
\end{array}\right.
$$

where the superscript $T$ denotes the matrix transpose operation, and the other variables and coefficients were as defined previously.

\subsection{Estimation of parameters}

All estimated coefficients of model (7) were significant ( $\alpha=0.05$ ) (Table 2). Coefficients $\beta_{3}$ and $\beta_{5}$ were positive, which implied that a warmer growing season or an increase in PWQ favored AGB accumulation. Coefficients $\beta_{2}$ and $\beta_{4}$ were negative, suggesting that excessive rain during the growing season, or high mean temperature in the wettest quarter, would decrease AGB. The negative coefficient for $L$ implied that the AGB of Masson pine tree of natural origin exceeded the AGB of planted trees. Coefficient $k_{1}$ was negative and $k_{2}$ was positive, which showed that the AGB values of trees with the same $S, D$, TGSP, MGST, MTWQ, and PWQ from the middle-subtropical zone were the highest, followed by those in the north- and south-subtropical zones. The positive sign of $\rho$ indicated that the model error terms were positively correlated with prediction residuals.

\subsection{Model evaluation}

Models (3) and (7) were further evaluated using both the calibration and validation datasets. The prediction accuracy of model (7) $(\bar{e}=5.18 \mathrm{~kg}, v=43.14$, RMSE $=43.45 \mathrm{~kg}$ for the calibration dataset; $\bar{e}=1.08 \mathrm{~kg}, v=45.75$, RMSE $=45.76 \mathrm{~kg}$ for the validation dataset) was much higher than that of model (3) $(\bar{e}$
$=5.30 \mathrm{~kg}, v=52.56, \mathrm{RMSE}=52.82 \mathrm{~kg}$ for the calibration dataset; $\bar{e}=7.87 \mathrm{~kg}, v=46.13$, RMSE $=46.80 \mathrm{~kg}$ for the validation dataset). Especially, the RMSE of model (7) based on the calibration dataset was $17.7 \%$ smaller than that of model (3), and the mean bias of model (7) based on the validation dataset was $86.3 \%$ lower than that of model (3). The residuals from the calibration data for model (7) displayed no discernable patterns, indicating that heteroscedasticity was effectively accounted for by the power variance function (Fig. 5b). Similar residual patterns were found for the validation dataset, and the error structures did not show any signs of autocorrelation (Fig. 4b).

\subsection{Potential effects of changing allometry on tree biomass estimates under future climate scenarios}

Figure 6 shows the box plots and distributions of the $R_{\mathrm{AGB}}$ in predicted AGB of Masson pine trees between the current and climate scenarios-RCP 2.6, RCP 4.5, and RCP 8.5-during the periods of 2041-2060 and 2061-2080 for the different climate zones (north-, middle-, and south-subtropical zones and the entire subtropical zone) and tree origins (natural and planed). The results indicated that both the increase and the decrease of AGB occurred in the subtropical China. Generally, the predicted values of tree AGB in three secondary climate zones under each climate scenario for the periods of 2041-2060 and 2061-2080 increased with the increased regional annual mean temperature and mean total precipitation. The differences of the increases in AGB among the climate zones for the same time period under three climate scenarios 
a

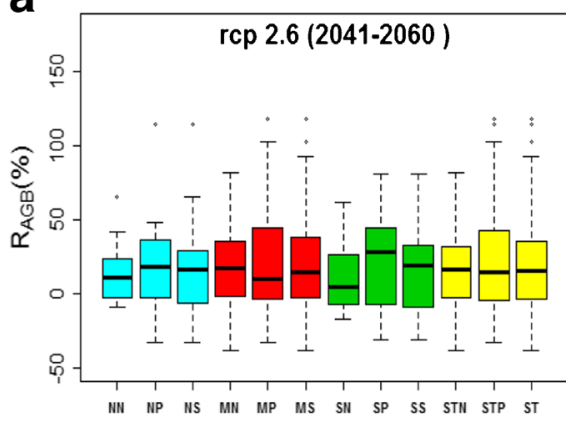

b

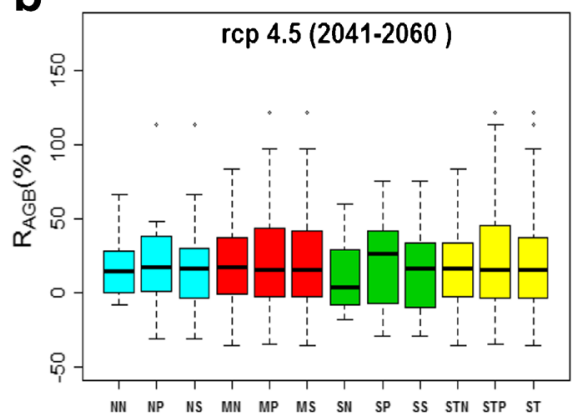

C

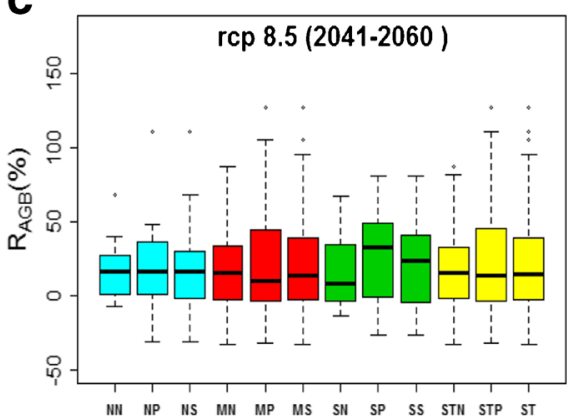

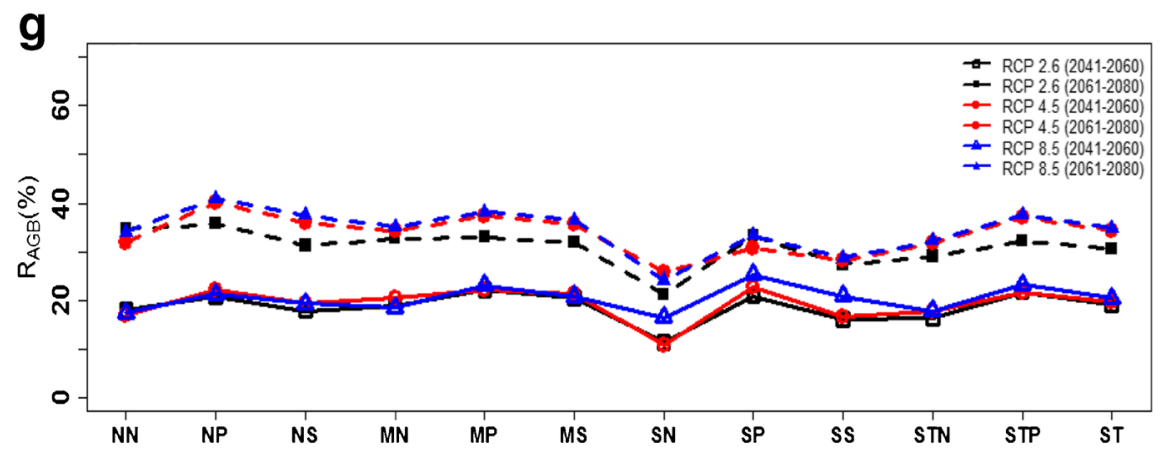

d

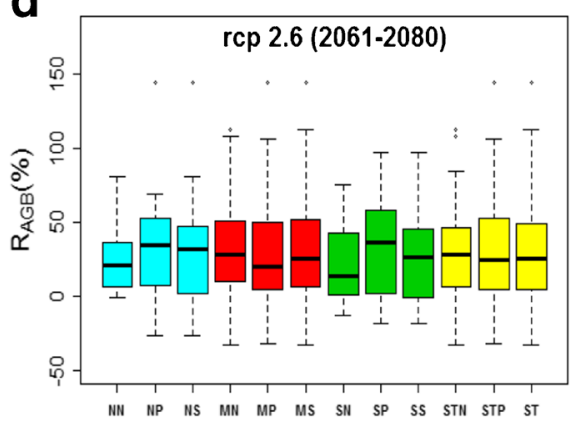

e

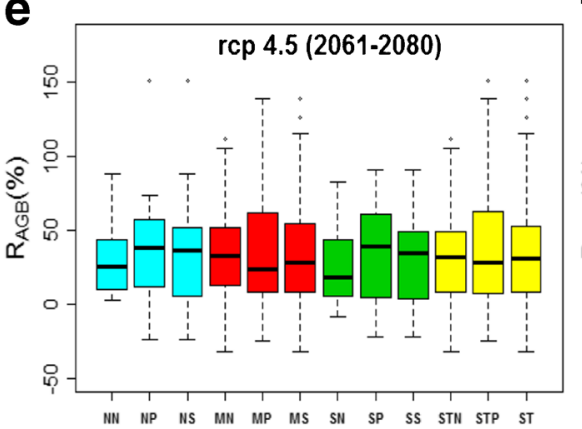

f

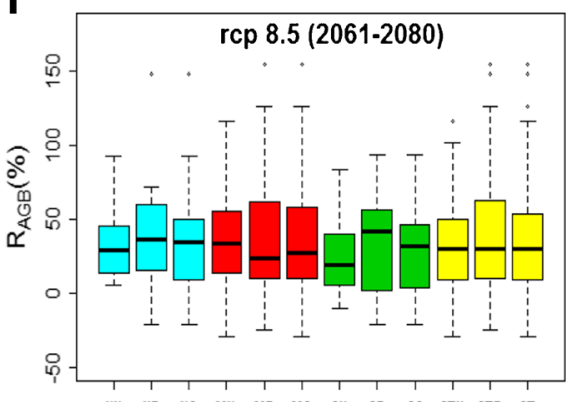

Fig. 6 The relative differences $\left(R_{\mathrm{AGB}}\right)$ in predicted aboveground biomass (AGB) of Masson pine trees between the current and future climate scenarios: RCP 2.6, RCP 4.5, and RCP 8.5 during the periods of 2041-2060 and 2061-2080 for three different secondary climate zones and the entire subtropical zone in China: a-f the box plots of $R_{\mathrm{AGB}}$ and $\mathbf{g}$ the distributions of the mean values of $R_{\mathrm{AGB}} ; N N, M N, S N$, and $S T N$

were substantially large (Fig. 6). The estimated average of AGB under each climate scenario in the secondary climate zones was the highest for the period 2061-2080, followed by the period 2041-2060, and the period 1950-2000 (Fig. 6g).

With other variables (e.g., $D$, secondary climate zone, and climate scenario) being equal, the estimated AGB of planted trees was higher than that of natural trees for the periods 2041-2060 and 2061-2080 (Fig. 6). The greatest increase in AGB was predicted for the planted trees in the northsubtropical zone for the period 2061-2080 under the RCP 8.5 climate scenario (overall increasing by $41.0 \pm 44.6 \%$ (mean \pm standard deviation) over the current AGB). For the time periods 2041-2060 and 2061-2080, Fig. 6g also shows that overall, the estimated average AGB under each secondary climate zone was the highest for the RCP 8.5 , followed by the denote trees of natural origin in the north-, middle-, and southsubtropical zones and the entire subtropical zone, respectively; $N P, M P$, $S P$, and $S T P$ denote trees of plantations in the north-, middle-, and southsubtropical zones and the entire subtropical zone, respectively; $N S, M S$, $S S$, and $S T$ denote all trees in the north-, middle- and south-subtropical zones and the entire subtropical zone

RCP 4.5, and the lowest for the RCP 2.6. The tree AGB of Masson pine in the entirety of the subtropical China was predicted to increase from the current levels under the RCP 2.6, RCP 4.5, and RCP 8.5 climate scenarios by $19.0 \pm 30.6$, $19.6 \pm 30.4$, and $20.5 \pm 31.0 \%$ for the period $2041-2060$ (Fig. 6a-c); by $30.6 \pm 33.6,34.5 \pm 34.7$, and $34.8 \pm 35.0 \%$ for the period 2061-2080 (Fig. 6d-f), respectively; and by $24.8 \pm 32.7,27.0 \pm 33.4$, and $27.7 \pm 33.8 \%$ for the whole periods 2041-2080, respectively.

\section{Discussion}

Tree growth and AGB accumulation differ with different climate, site conditions, and management practices (Landsberg 
and Sands 2011). Climate variables need to be incorporated into AGB models of trees if these models are utilized to directly account for the impact of changing climate on tree biomass accumulation. This can be accomplished, at least in the composite model form (e.g., Wykoff 1990), by modifying the intercept term (i.e., $\beta_{0}$ ) in biomass models such as model (2). In this study, it was assumed that climatic variables only influence the allometric scale of AGB equation with the observation of a universal allometric power (West et al. 1997, 1999; Vieilledent et al. 2012; Anitha et al. 2015) although there were some exceptions (Chave et al. 2005). The space-time replacement approach (Pickett 1989) was applied in this study to develop the climate-sensitive AGB model. Results showed that the inclusion of climate variability in the allometric scale of the biomass equation yielded improved estimation and the scale power was close to $8 / 3$ which supported our assumption.

It was found that a combination of the temperature- and precipitation-related variables (TGSP, MTWQ, MGST, and PWQ) was significant in explaining the variation in AGB of Masson pine trees across three secondary climate zones in the subtropical China. The modeling results indicated that more precipitation over the growing season negatively affected the AGB of Masson pine trees. Previous studies indicated that the relationship between mean annual precipitation and tree AGB or net primary productivity, on the most of sites, could be described by a nonlinear, concave-down function (Hsu et al. 2012). The decline in the AGB was likely an indirect effect mediated by the availability of other resources (Hsu et al. 2012; Subedi and Sharma 2013). While additional moisture usually increases tree biomass in dry-to-mesic ecosystems, increasing precipitation in humid ecosystems may reduce tree biomass by decreasing radiation, increasing nutrient leaching, or reducing soil oxygen availability (Schuur 2003; Hsu et al. 2012). Increasing precipitation may also reduce the diffusion of oxygen through water-filled pores, as well as decomposition rates (Subedi and Sharma 2013). In addition, the results that an increase in precipitation led to the decrease of AGB could be also explained by biological traits of Masson pine. For example, Masson pine trees mostly grow well in the ridges of hills or mountains with good light and dry sites (Xia et al. 1996; Zhang et al. 2013).

However, more precipitation during the wettest quarter positively impacted the AGB of Masson pine trees in our model. The wettest period in the subtropical China occurs during the months of May, June, July, and August (falling in the second and third quarters). This period also has the highest yearly temperatures (Yang et al. 2006); thus, it had the highest AGB of Masson pine trees. This is consistent with the findings from the previous study by Zhang et al. (2013).

Understanding seasonal growth patterns of the subtropical coniferous trees is important to explain the relationship between moisture availability and tree AGB. In the case for temperate trees (Tardif et al. 2001), the cumulative annual biomass growth of Masson pine trees can be described using three distinct phases. In March to April, an initial period of swelling of a stem occurs, indicating the upward passage of water. This is followed by the period (May-November) of active cell division, indicating the "grand period" of growth. During the third period (December to February), tree growth stops, the cells dehydrate, and the cambial tissue rests. Optimal growing conditions during the grand period are very important for Masson pine trees. The positive relationship that we found between increased moisture availability during the "grand period of growth" and AGB was as expected.

It was found that a warmer growing season increased the AGB of Masson pine trees, which is consistent with previous findings (e.g., Gholz 1982). The warming-induced increase in tree productivity may be a direct effect of either increased photosynthesis at higher temperatures, longer growing seasons, or an indirect effect of increased nutrient availability, resulting from increased rates of litter decomposition and $\mathrm{N}$ mineralization. Both the direct and indirect effects of the warming could be particularly important in the northsubtropical zone in which both temperature and nutrient limitations are more critical relative to the other two subzones.

The mean temperature during the wettest quarter appeared to be the main factor in limiting AGB of trees (Table 2). It is likely that increasing temperatures increase evaporative demand, causing increased water stress, which may impact tree growth more strongly than the increase in temperature alone (Ciais et al. 2005). The temperature in the subtropical China in the wettest quarter is quite high overall, thereby increasing evapotranspiration and reducing the availability of soil moisture to trees. Therefore, trees in this period may have less available moisture for photosynthesis and consequently, lower growth. This is also supported by a simulation study of seasonal photosynthesis in the northwest USA, which indicated that growing-season photosynthesis was greatly restricted by drought (Emmingham and Waring 1977).

The results showed that there was the highest AGB of Masson pine trees in the middle-subtropical zone, followed by the north- and south-subtropical zones (Table 2; Fig. 6). This ranking is similar to that found by Yang et al. (2006). In the middle-subtropical zone, the number of days without frost, or with a mean daily temperature $\geq 10{ }^{\circ} \mathrm{C}$, is more than 230 days, the corresponding accumulated temperature is above $5000{ }^{\circ} \mathrm{C}$, and the range of annual mean precipitation is $1000-2500 \mathrm{~mm}$. These are favorable conditions for tree growing (Yang et al. 2006). In the north-subtropical zone, although there is abundant precipitation (the range of annual mean precipitation is $800-1800 \mathrm{~mm}$ ), the temperature slightly lower than that in the middle-subtropical zone reduces the potential for tree growing (Yang et al. 2006). In the southsubtropical zone, precipitation is quite close to the middlesubtropical zone, but the mean temperature is higher. Therefore, the evaporation in this subregion is higher than that 
in the middle-subtropical zone, which, in turn, decreases the biomass of trees (Yang et al. 2006).

When the effects of future climate change on AGB using the climate-sensitive AGB model developed in the study were analyzed, ideally, the $D$ growth of sample trees should be predicted related to climate change (Zeng et al. 2017). The climatic impacts on AGB of each sample tree under climate change scenarios should be then analyzed. However, in practice, in addition to climatic zones and climatic-related variables, other factors, such as tree height, crown size, development stage, forest types, site characteristics, stand structure, stand density (including tree recruitment and death), and competition, might significantly contribute to the variation in the individual tree $D$ (Subedi and Sharma 2013; Ashraf et al. 2015). Some of these factors interact with each other and vary with future climate change, which would result in the complexity and very large uncertainty in future AGB estimates of sample trees for this method when $D$ growth is considered. In addition, a fixed allometric power in the power-law relationship between tree biomass and $D$ was commonly assumed in the biomass modeling, which was further verified in this study (Table 2). Relative to traditional biomass allometric equations [e.g., model (1)], the developed climate-sensitive AGB model [model (7)] accounted for potential climate-biomass relationships effectively (Table 2 ) by parameterization of allometric scale. Thus, the effects of different future climate scenarios on AGB variation were evaluated under the constraint of the same $D$ in this study. Additionally, the effects of wood density on AGB were also observed (Zhang et al. 2012; Deng et al. 2014) and used for improving biomass estimation (Chave et al. 2014). Unfortunately, we did not measure the wood density of each sample tree in the data collection. But, the effect of wood density may be indirectly reflected by climatic factors and random effects.

According to the climate-sensitive AGB model developed in the study, we estimated the AGB of Masson pine trees in the subtropical China under future climate changes and found that the AGB would increase by 10.91 to $41.01 \%$ under the RCP 2.6, RCP 4.5, and RCP 8.5 climate scenarios for the period 2041-2080 (Fig. 6). Therefore, traditional biomass equation without climate variables will produce some bias in biomass and carbon estimation as expected. The magnitude of the effects of climate change on AGB revealed the variation and uncertainty of AGB predictions with stand origin, climate zones, and climate scenarios. Our study also showed clear positive effects of future climate change on AGB of Masson pine trees. Medlyn et al. (2011) summarized the uncertainties about the effects of climate change in terms of direction and magnitude on forest productivity due to the differences in model strategy, climate variables, climate scenarios, tree species, and regions. The uncertainties need to further be addressed when the potential factors affecting tree biomass are investigated in the future.
Acknowledgements The article was funded by the Forestry Public Welfare Scientific Research Project (No. 201504303) and the Chinese National Natural Science Foundation (Nos. 31470641, 31300534, and 31570628). We appreciate the valuable comments from the chief editor Dr. Erwin Dreyer, Dr. Jean-Michel Leban, the handling editor, and two anonymous reviewers who improved the manuscript.

Compliance with ethical standards The biomass data used in this study were collected according to the protocol of data collection for tree biomass modeling which was drafted by the State Forestry Administration of China (SFA 2014).

\section{References}

Anitha K, Verchot LV, Joseph S, Herold M, Manuri S, Avitabile V (2015) A review of forest and tree plantation biomass equations in Indonesia. Ann Forest Sci 72(8):981-997

Ashraf MI, Meng F-R, Bourque CP-A, MacLean DA (2015) A novel modelling approach for predicting forest growth and yield under climate change. PLoS One 10(7):e0132066. doi:10.1371/journal. pone. 0132066

Boisvert-Marsh L, Périé C, de Blois S (2014) Shifting with climate? Evidence for recent changes in tree species distribution at high latitudes. Ecosphere 5:1-33

Chave J, Andalo C, Brown S, Cairns MA, Chambers JQ, Eamus D, Folster H, Fromard F, Higuchi N, Kira T, Lescure JP, Nelson BW, Ogawa H, Puig H, Riera B, Yamakura T (2005) Tree allometry and improved estimation of carbon stocks and balance in tropical forests. Oecologia 145:87-99

Chave J, Réjou-Méchainn M, Burquez A, Chidumayo E, Colgan MS, Delitti Welington BC et al (2014) Improved allometric models to estimate the aboveground biomass of tropical trees. Glob Chang Biol 20(10):3177-3190

Ciais P, Reichstein M, Viovy N, Granier A, Ogee J, Allard V, Aubinet M, Buchmann N, Bernhofer C, Carrara A (2005) Europe-wide reduction in primary productivity caused by the heat and drought in 2003 . Nature 437:529-533

Daniels LD, Veblen TT (2004) Spatiotemporal influences of climate on altitudinal tree line in northern Patagonia. Ecology 85:1284-1296

Davidian M, Giltinan DM (1995) Nonlinear models for repeated measurement data. Chapman and Hall, New York

Deng X, Zhang L, Lei P, Xiang W, Yan W (2014) Variations of wood basic density with tree age and social classes in the axial direction within Pinus massoniana stems in Southern China. Ann Forest Sci 71(4):505-516

Diéguez-Aranda U, Burkhart HE, Amateis RL (2006) Dynamic site model for loblolly pine (Pinus taeda L.) plantations in the United States. For Sci 52:262-272

Eggers J, Lindner M, Zudin S, Zaehle S, Liski J (2008) Impact of changing wood demand, climate and land use on European forest resources and carbon stocks during the 21 st century. Glob Chang Biol 14:2288-2303

Emmingham WH, Waring RH (1977) An index of photosynthesis for comparing forest sites in western Oregon. Can J For Res 7:165-174

Feng X, Cheng R, Xiao W, Wang R, Wang X, Cao B (2011) Effects of air temperature in growth season on Masson pine (Pinus massoniana) radial growth in north subtropical region of China. Chin J Ecol 30: 650-655 (In Chinese with English abstract)

Fu L, Zeng W, Zhang H, Wang G, Lei Y, Tang S (2014a) Generic linear mixed-effects individual-tree biomass models for Pinus massoniana Lamb. in Southern China. South Forests 76(1):47-56 
Fu L, Wang M, Lei Y, Tang S (2014b) Parameter estimation of two-level nonlinear mixed effects models using first order conditional linearization and the EM algorithm. Comput Stat Data An 69:173-183

Fu L, Lei Y, Wang G, Bi H, Tang S, Song X (2016) Comparison of seemingly unrelated regressions with multivariate errors-invariables models for developing a system of nonlinear additive biomass equations. Trees 30:839-857

Gao X, Shi Y, Zhang D, Giorgi F (2012) Climate change in China in the 21 st century as simulated by a high resolution regional climate model. Chin Sci Bull 57:1188-1195 (In Chinese with English abstract)

Gholz HL (1982) Environmental limits on aboveground net primary production, leaf area, and biomass in vegetation zones of the Pacific Northwest. Ecology 63:469-481

Hamann A, Wang T (2006) Potential effects of climate change on ecosystem and tree species distribution in British Columbia. Ecology $87: 2773-2786$

Hijmans RJ, Cameron SE, Parra JL, Jones PG, Jarvis A (2005) Very high resolution interpolated climate surfaces for global land areas. Int $\mathrm{J}$ Climatol 25:1965-1978

Hsu JS, Powell J, Adler PB (2012) Sensitivity of mean annual primary production to precipitation. Glob Chang Biol 18:2246-2255

Huang B (1992) On the boundary of tropics in China: I. Definition of tropical and subtropical zones in internation. Sci Geogr Sin 12:97104 (In Chinese with English abstract)

Intergovernmental Panel on Climate Change (IPPC) (2001) Climate change 2001. Synthesis report. In: Watson RT, Albritton DL, Baker T, Bashmakov IA, Canziani O, Christ R (eds) A contribution of Working Groups I, II, and III to the Third Assessment Report of Intergovernmental Panel on Climate Change. Cambridge University Press, Cambridge, p 398pp

IPCC (2013) Summary for policy-makers. In: Stocker TF, Qin D, Plattner G-K, Tignor M, Allen SK, Boschung J, Nauels A, Xia Y, Bex V, Midgley PM (eds) Climate change 2013: the physical Science basis. Contribution of Working Group I to the Fifth Assessment Report of the Intergovernmental Panel on Climate Change. Cambridge University Press, Cambridge and New York, NY

Jiang H, Radtke PJ, Weiskittel AR, Coulston JW, Guertin PJ (2015) Climate- and soil-based models of site productivity in eastern US tree species. Can J For Res 45:325-342

Keith H, Mackey BG, Lindenmayer DB (2009) Re-evaluation of forest biomass carbon stocks and lessons from the world's most carbondense forests. PNAS 106:11635-11640

Landsberg JJ, Sands P (2011) Physiological ecology of forest production: principles, processes and models. Academic Press, London

Lei X, Yu L, Hong L (2016) Climate-sensitive integrated stand growth model (CS-ISGM) of Changbai larch (Larix olgensis) plantations. For Ecol Manag 376:265-275

Lin D, Lai J, Muller-Landau HC, Mi X, Ma K (2012) Topographic variation in aboveground biomass in a subtropical evergreen broadleaved forest in China. PLoS One 7:e48244. doi:10.1371/journal. pone. 004824

Marlon JR, Bartlein PJ, Carcaillet C, Gavin DG, Harrison SP, Higuera PE (2008) Climate and human influences on global biomass burning over the past two millennia. Nature 1:697-702

Medlyn BE, Duursma RA, Zeppel MJ (2011) Forest productivity under climate change: a checklist for evaluating model studies. WIRES Climate Change 2:332-355

Monleon VJ, Lintz HE (2015) Evidence of tree species' range shifts in a complex landscape. PLoS One 10:e118069. doi:10.1371/journal. pone. 0118069

Peng C, Ma Z, Lei X, Zhu Q, Chen H, Wang W, Liu S, Li W, Fang X, Zhou X (2011) A drought-induced pervasive increase in tree mortality across Canada's boreal forests. Nat Clim Chang 1:467-471

Pickett S (1989) Space-for-time substitution as an alternative to long-term studies. In: Likens GE (ed) Long-term studies in ecology: approaches and alternatives. Springer, New York, pp 110-135
Pinheiro JC, Bates DM (2000) Mixed-effects models in S and S-PLUS. Springer-Verlag, New York, NY

Poudel BC, Sathre R, Gustavsson L, Bergh J, Lundström A, Hyvönen R (2011) Effects of climate change on biomass production and substitution in north-central Sweden. Biomass Bioenergy 35:4340-4355

R Development Core Team (2011) R: a language and environment for statistical computing. R Foundation for Statistical Computing, Vienna Available at: http://www.r-project.org (accessed 4 September 2011)

Schuur EAG (2003) Productivity and global climate revisited: the sensitivity of tropical forest growth to precipitation. Ecology 84:11651170

SFA (State Forestry Administration) (2012) China's forestry 2006-2010. China Forestry Publishing House, Beijing (In Chinese)

SFA (State Forestry Administration) (2014) Technical regulation on sample collections for tree biomass modeling. Standards Press of China, Beijing (In Chinese)

Shuman JK, Shugart HH (2009) Evaluating the sensitivity of Eurasian forest biomass to climate change using a dynamic vegetation model. Environ Res Lett 4:1-7

Sinervo B, Méndez-de-la-Cruz F, Miles DB (2010) Erosion of lizard diversity by climate change and altered thermal niches. Science 328:894-899

Stegen J, Swenson N, Enquist B, White E, Phillips O, Jorgensen P, Weiser M, Mendoza AM, Vargas PN (2011) Variation in above-ground forest biomass across broad climatic gradients. Glob Ecol Biogeogr 20:744-754

Strömgren M, Linder S (2002) Effects of nutrition and soil warming on stemwood production of a boreal Norway spruce stand. Glob Chang Biol 8:1195-1204

Subedi N, Sharma M (2013) Climate-diameter growth relationships of black spruce and jack pine trees in boreal Ontario, Canada. Glob Chang Biol 19:505-516

Tardif J, Flannigan M, Bergeron Y (2001) An analysis of the daily radial activity of 7 boreal tree species, northwestern Quebec. Environ Monit Assess 67:141-160

Tian X, Sohngen B, Kim JB, Ohrel S, Cole J (2016) Global climate change impacts on forests and markets. Environ Res Lett 11:035011

Trincado G, Burkhart HE (2006) A generalized approach for modeling and localizing stem profile curves. For Sci 52:670-682

Vieilledent G, Vaudy R, Andriamanohisoa SFD, Rakotonarivo OS, Randrianasolo HZ et al (2012) A universal approach to estimate biomass and carbon stock in tropical forests using generic allometric models. Ecol Appl 22(2):572-583

West GB, Brown JH, Enquist BJ (1997) A general model for the origin of allometric scaling laws in biology. Science 276:122-126

West GB, Brown JH, Enquist BJ (1999) A general model for the structure and allometry of plant vascular systems. Nature 400:664-667

Wilmking M, Juday GP, Barber VA, Zald HSJ (2004) Recent climate warming forces contrasting growth responses of white spruce at treeline in Alaska through temperature thresholds. Glob Chang Biol 10:1724-1736

Wykoff WR (1990) A basal area increment model for individual conifers in the northern Rocky Mountains. For Sci 36:1077-1110

Xia B, Lan T, He S (1996) Nonlinear response function of growth of Pinus massoniana to climate. Chin J Plant Ecol 20(1):51-56

Xiang W, Liu S, Deng X, Shen A, Lei X, Tian D, Zhao M, Peng C (2011) General allometric equations and biomass allocation of Pinus massoniana trees on a regional scale in southern China. Ecol Res 26:697-711

Yang Q, Zheng D, Wu S (2006) On subtropical zone of China. J Subtrop Res Environ 1:1-10 (In Chinese with English abstract)

Zeng WS, Zhang HR, Tang SZ (2011) Using the dummy variable model approach to construct compatible single-tree biomass equations at different scales-a case study for Masson pine 
(Pinus massoniana) in southern China. Can J For Res 41: $1547-1554$

Zeng W, Duo H, Lei X, Chen X, Wang X, Pu Y, Zou W (2017) Individual tree biomass equations and growth models sensitive to climate variables for Larix spp. in China. Eur J Forest Res. doi:10.1007/ s10342-017-1024-9
Zhang L, Deng X, Lei X, Xiang W, Peng C, Lei P, Yan W (2012) Determining stem biomass of Pinus massoniana $\mathrm{L}$. through variations in basic density. Forestry 85(5):601-609

Zhang L, Deng X, Lei X, Zhao Z, Xiang W, Yan W (2013) Pinus massoniana productivity at different age stages in relation to climatic factors. Chin J Ecol 32:1104-1110 (In Chinese with English abstract) 